\title{
Comparative Analysis of Ellipsoidal Height and Shuttle Radar Topographic Mission Elevation
}

\author{
IJAWARE, VA \\ Department of Surveying and Geoinformatics, Federal University of Technology, Akure, Ondo State, Nigeria \\ Corresponding Author Email:vaijaware@futa.edu.ng
}

\begin{abstract}
Ellipsoidal elevation represents a precise geospatial data type within the analysis and modelling of various hydrological and ecological phenomenon required in preserving the human environment. Likewise, Shuttle Radar Topographic Mission (SRTM) has created an unparalleled data set of global elevations that are freely available for modelling ubiquitous environmental applications. This research aims to carry out a comparative analysis of ellipsoidal heights and SRTM heights with the following objectives: downloading DEM's (SRTM) data covering the study area, determining the spot heights within the boundary in conventional method, extract DEM'S heights within the boundary of the study area, and compared the heights in the conventional method with DEM'S heights. South GPS and Leica Total Station were used to acquire data for control extension and spot heightening respectively while the elevation of SRTM data was obtained by transforming the X and $\mathrm{Y}$ data from GPS observation to Longitude and Latitude before using ArcGIS 10.6 to extract the elevation of the boundary pillar and all the spot heights which were relatively compared in terms of its products- heights, contour, 3-D wireframe, 3-D surface model, and overlaid of contour on shaded relief. The results of the study showed that vertical difference using conventional method and SRTM dataset ranges between $-2.345 \mathrm{~m}$ to $11.026 \mathrm{~m}$. Also, the hypothesis tested using a two-tail student $\mathrm{t}$-test and F-test revealed that one mean is not significantly different from the other at $95 \%$ confidence level. The research recommends that the products obtained for the two systems can be used interchangeably.
\end{abstract}

DOI: https://dx.doi.org/10.4314/jasem.v24i8.14

Copyright: Copyright $(\mathrm{C} 2020$ Ijaware. This is an open access article distributed under the Creative Commons Attribution License (CCL), which permits unrestricted use, distribution, and reproduction in any medium, provided the original work is properly cited.

Dates: Received: 30 May 2020; Revised: 03 July 2020; Accepted: 05August 2020

Keywords: Shuttle radar topographic mission, Ellipsoidal elevation, contour, 3D wireframe, 3D surface model

Digital Elevation Models (DEM) provides basic heights information of the Earth's surface and features upon it. It includes the heights of vegetation, buildings and other surface features, and only gives elevations of the terrain in areas where there's little or no ground cover. DEMs have become a crucial data source for a variety of applications in Earth and environmental sciences. Generally, DEM datasets are often obtained from range of techniques, like as ground survey e.g., airborne photogrammetric imagery (Kahmen and Faig, 1988), airborne laser scanning ASPRS (1996), radar altimetry (Lohr, 1998), and Interferometric Synthetic Aperture Radar (InSAR) (Hilton et al., 2003).Very often, DEMs are constructed from data sourced from several of these methods and are thus of variable quality.The range of ground-based and airborne topographic surveying equipment capable of sub-decimeter to sub-centimeter precision within the horizontal and vertical direction includes Total Stations, Real time kinematic GPS, Terrestrial Laser Scanner and airborne LiDAR. Each of those equipment possesses techniques which will be used to collect spatially explicit XYZ coordinates of earth features. Specifically,ellipsoidalheight is used to depict terrain relief and is particularly relevant for various applications like soil erosion, volume calculations, flood estimate, quantification of earthworks for channels, roads, dams, embankment etc. This research aimed at comparing ellipsoidal height and Shuttle Radar Topographic Mission elevation with a view of solving the problem of non availability of up-to-date information about the hilly nature of the study site, lack of data for computing the amount and rate of runoff, and terrain configuration, which will serve as an important tool for future physical development of the study siteexplained why it remain neglected for more than three decades. However, previous studies like Gorokhovich and Voustianiouk (2006); Ozah and Kufoniyi (2008); Hirt et al (2010) Isioye and Obarafo (2010) Mukul et al (2015) and Nwilo et al (2012) among others assessed the accuracies of SRTM while Forkuor and Maathuis 2012; Isioye and Yang, 2013 and. Nwilo et al (2017) based their studies on the comparison of SRTM and ASTER Derived Digital Elevation Models. None of these studies compared ellipsoidal heights and SRTM in their study area which is the gap this research seeks 
to fill thereby forming a referral and benchmark for future research in the study area.

The following questions deserve immediate answers if the goal of the research is to be reached: (i.) What are the latitudes and longitudesofSRTM data covering the study area? (ii.) What are the conventional 3-D coordinates of the boundary of the study area? (iii.) What are the spot heights values within the boundary of the study area using conventional method and SRTM? and (v.) what are the differences between the heights of the two methods and their products? In other to achieve the laudable aim of the research and to also proffer substantive solutions, GPS and Total Station were used for the data acquisition from the field while SRTM data was downloaded from the International Agriculture Research Consortium for Spatial Information (CGIAR-CSI) website. The analysis of the height difference was carried out to determining the best out of the two approaches and find out statistically if the two datasets are equal or different from each other.

\section{MATERIALS AND METHODS}

Study Area: The study area as shown in Figure 1 is located at the Southern part of the Federal University of Technology Akure, in Akure South Local government Ondo State. Specifically, the area is along Oba Adebiyi Adesida road off Oduduwa road with latitude $07^{\circ} 17^{\circ} 47^{\prime \prime}$ and longitude $0508^{\prime} 31^{\prime \prime} \mathrm{NE}$ and latitude $07^{\circ} 17^{\circ} 42^{\prime \prime}$ and longitude $05^{\circ} 08^{\prime} 23^{\prime \prime}$ SW. It covers about 568 hectares. The average annual rainfall is $1215 \mathrm{~mm}$ and it last between April and October every year while the average elevation is about $374 \mathrm{~m}$.

Data collection and processing: The methodology adopted in this research is in three stages: Data acquisition, Data processing and analysis, and information presentation. Both primary data and secondary data was employed in this study. The primary data involve the use of Differential GPS to establish a frame work which serves as control points for the research work while Total Station was used for fixing the perimeter boundary, detailing and Spot heightening.Similarly, the secondary data was from SRTM C-band digital elevation model (DEM) version 4.1 in $90 \mathrm{~m}$ resolution of one of the tiles covering the chosen study site downloaded from the Consultative Group for International Agriculture Research Consortium for Spatial Information (CGIAR-CSI) website. The SRTM is seamless with all voids filled using a methodology based on spatial filtering in line with Gorokhovich and Voustianiouk (2006). The downloaded SRTM data was in Longitude and Latitude format projected on the WGS 84 Ellipsoid.

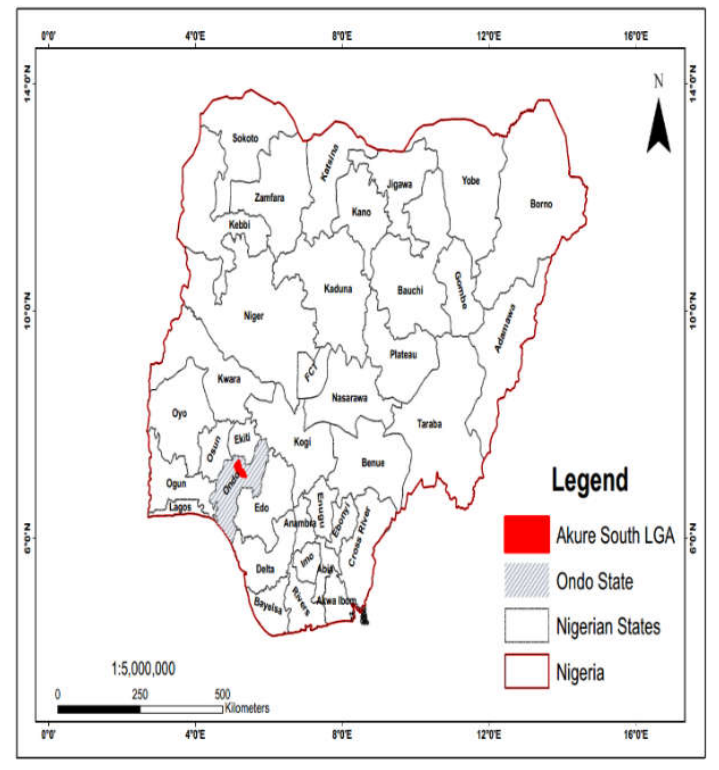

Fig 1: Study Area

The data captured during this research were transferred to the computer and the processing carried out includes numerical calculation, classification of data and transmission of data from one place to another.In order to extract the elevation of SRTM dataset,Franson Coordinate translation software version 2.3 was used to transformed the $\mathrm{X}$ and $\mathrm{Y}$ of the perimeter, details and the spot heightdata (conventional method) into longitude and latitude formatand wassubsequently used to extract the elevation of SRTM dataset. Using ArcGIS 10.6, elevation of the boundary pillars and the entire spot heightsof the SRTM equivalent were extracted and exported to form shapefile.

\section{RESULTS AND DISCUSSION}

After the SRTM extraction, the final coordinate and elevation of data from both the conventional method of data acquisition and SRTM with the difference in height were shown in Table 1.From the table, the vertical difference between the conventional method of data acquisition and SRTM dataset range between $2.345 \mathrm{~m}$ to $+11.026 \mathrm{~m}$ shown as figure 2 . The height $(\mathrm{Z})$ obtained for the conventional method for points identified as PG/17/44 has the highest value of 382.813 while point identified as $\mathrm{PG} / 17 / 49$ has the least height of $362.807 \mathrm{~m}$. Also, points identified as PG/17/43 and PG/17/50 has the highest and lowest heights of $381.308 \mathrm{~m}$ and $372.605 \mathrm{~m}$ respectively for the SRTM. The difference between the highest and the lowest elevations for both the conventional method and SRTM was $20.006 \mathrm{~m}$ and $8.703 \mathrm{~m}$ respectively. The $Z$ values for the conventional method represent the terrain better than the $Z$ values of SRTM because of tree canopies that dominated the study site. 
Table 1: Elevation Differences between Conventional Method and SRTM

\begin{tabular}{llllllll}
\hline Easting & Northing & Longitude & Latitude & Z CONV. MTD & Z SRTM & $\boldsymbol{\Delta ~ Z}$ & ID \\
\hline 736343.93 & 806973.405 & 5.1398966 & 7.2965543 & 379.144 & 381.308 & 2.164 & PG/17/43 \\
736434.697 & 806968.055 & 5.1407181 & 7.296502 & 382.813 & 380.468 & -2.345 & PG/17/44 \\
736541.152 & 806961.785 & 5.1416816 & 7.2964408 & 374.944 & 375.839 & 0.895 & PG/17/45 \\
736564.165 & 806960.402 & 5.1418899 & 7.2964273 & 370.623 & 373.589 & 2.966 & PG/17/46 \\
736557.124 & 806882.411 & 5.1418228 & 7.2957226 & 376.399 & 374.110 & -2.289 & PG/17/47 \\
736549.109 & 806791.302 & 5.1417463 & 7.2948993 & 363.741 & 374.263 & 10.522 & PG/17/48 \\
736543.678 & 806786.605 & 5.141697 & 7.2948571 & 362.807 & 373.833 & 11.026 & PG/17/49 \\
736328.695 & 806799.032 & 5.1397512 & 7.2949787 & 373.565 & 372.605 & -0.960 & PG/17/50 \\
\hline \multicolumn{7}{c}{ Source: Author's field work }
\end{tabular}

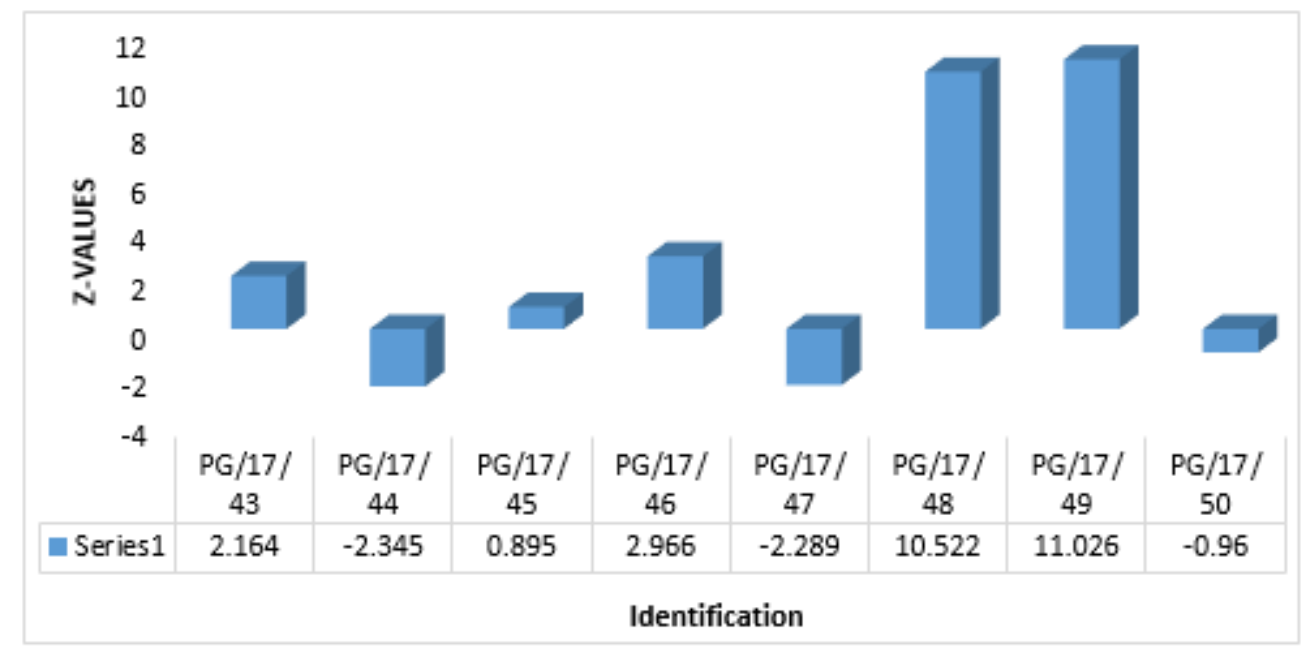

Fig 2: Elevation Difference between conventional method and SRTM

The perimeter boundary, spot heights and details were plotted with AutoCAD 2016 while the contour and Digital Terrain Model (DTM) was generated using Surfer 16.0 software. Specifically, the final coordinates obtained from the boundary points with the Total station based on closed horizon method of horizontal angle observation, were used for plotting the perimeter/ boundary points while the spot heights, detailing and subsequently contouring were produced from the provisional coordinate obtained directly from the field using the Total Station theodolite(figures 3a and $3 b)$.

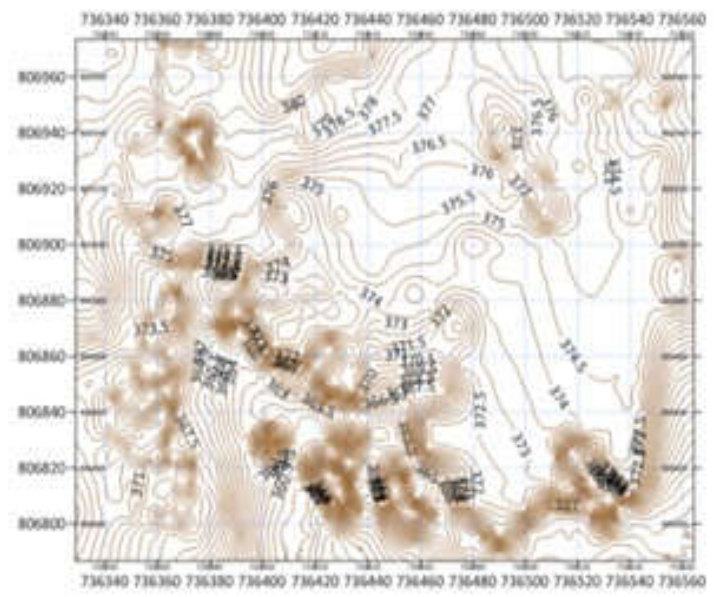

Fig3a: Terrain and Contour (Conventional).

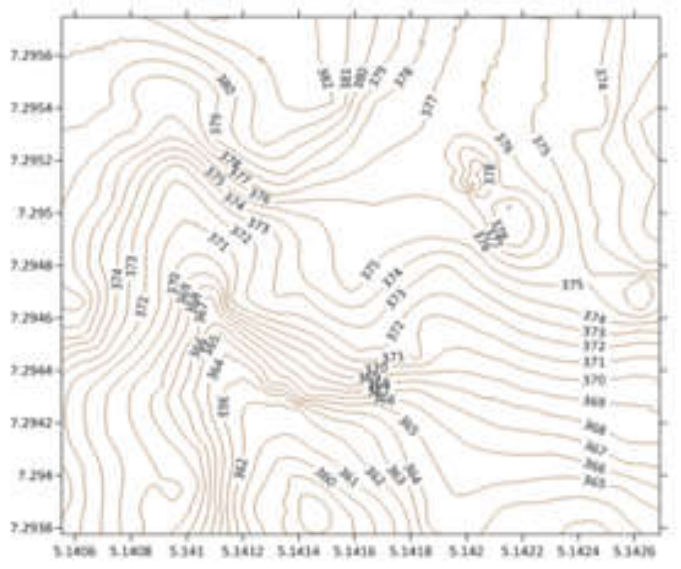

Fig 3b: Terrain and Contour (SRTM)

From the contour,the difference in elevation between the minimum contour level $(356 \mathrm{~m})$ and the maximum $(383 \mathrm{~m})$ was $27 \mathrm{~m}$. Based on the criteria that numerous contour lines which are closer to one another indicate hilly terrain and when further apart indicate a gentle slope. It can be inferred from the research that the study area is hilly with few areas as gentle slope and large area with steeply slope. The research revealed that figure $3 \mathrm{a}$ show more steepness than figure $3 \mathrm{~b}$. Also, figure $3 \mathrm{a}$ present the study area as hilly area 
while this was not so in figure $3 \mathrm{~b}$. Although data acquisition in the field was more tedious for the conventional method when compared to the SRTM. The conventional method is adjudged to be more suitable in representing terrain and contour in the study area. Similarly, 3D Wireframe modelling for the study area shown asfigures $4 \mathrm{a}$ and $4 \mathrm{~b}$ for conventional method and SRTM respectively contains information about the locations of all the points (vertices) and edges in space coordinates.

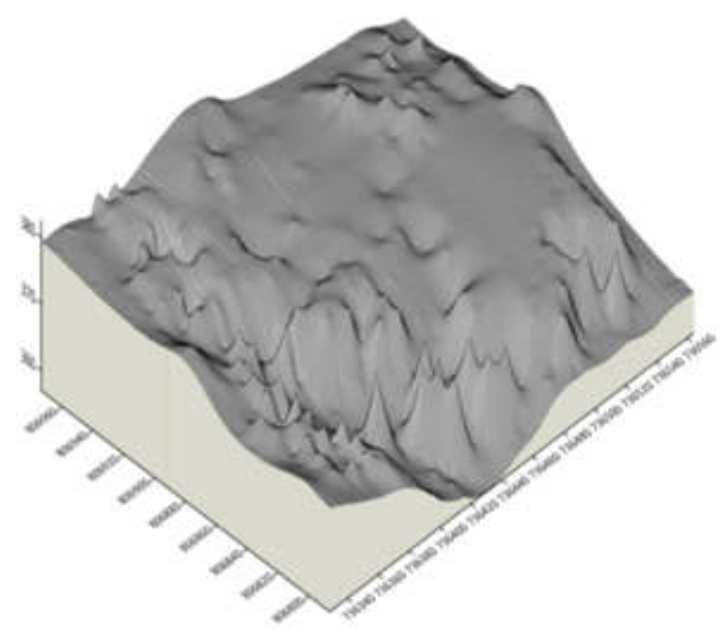

Fig 4a: 3-D Wireframe (Conventional)

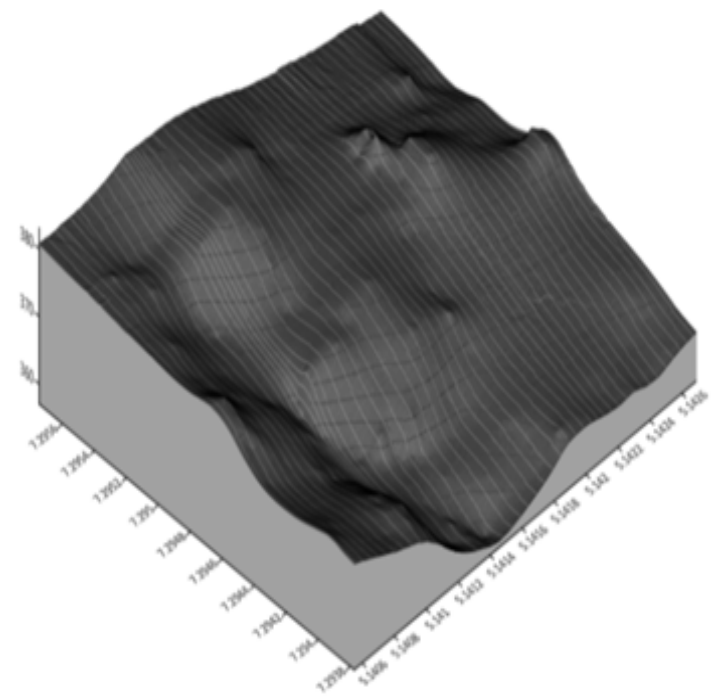

Fig4b: 3-D Wireframe (SRTM)

Each vertex is defined by $\mathrm{x}, \mathrm{y}, \mathrm{z}$ coordinate and it efficiently convey information than multi view drawings because, it contains information needed to create surface, solid and higher order models to aid object visualization in terms of slope and hydrology of the study area. Figure 4 a revealed a rugged hilly with disjointed surface while figure $4 \mathrm{~b}$ shows a smooth surface and a continuously connected wireframe surface as well as realistic looking and dense grid solid surface. Essentially, typical barrier morphology with shadow are seen in figure $4 \mathrm{~b}$, but is somehow missing in figure 4a. Also, sediment traps and soak holes which was seen during ground thruthing characterised figure $4 \mathrm{a}$ while it is completely absent in figure $4 \mathrm{~b}$. For this, the 3-Dwireframe from conventional method seems well suited for representing and visualizing terrain objects in the study area.
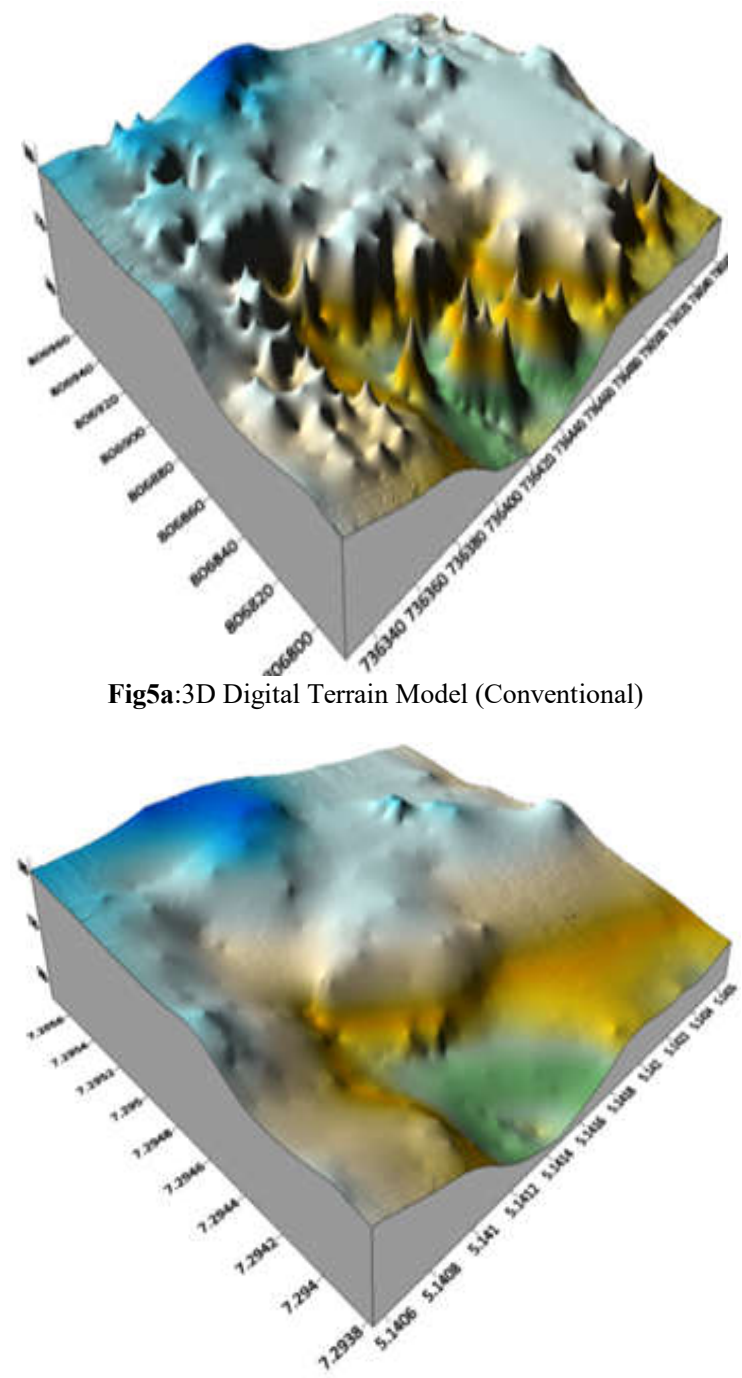

Fig 5b:3D Digital Terrain Model(SRTM)

A digital terrain models (DTMs) shown in figures 5a and $5 \mathrm{~b}$ is a continuous surface that describe the bare ground topography and terrain, such as slope or skeleton of the study area. It specifically shows the representation of the terrain in three dimensions such that, spatial problem like aspect and slope can be resolved faster. Specifically, figure 5a shows the roughness of the terrain where the valley contains sediment trap and soak holes but this attributes were 
completely absent in figure $5 \mathrm{~b}$, because, the SRTM present the study area as a smooth surface with gentle slope instead of steep slope. During rainfall, erosion laden with noise characterized figure $5 \mathrm{a}$ but figure $5 \mathrm{~b}$ may not produce a notable noise after rainfall. With this information, DTM of conventional method represent the bare ground elevation of the study area better than the SRTM.Notably too, when the contour map was overlaid on shaded relief, the hilly and the valley part as well as the steeps and the gentle slope of the study area was clearly revealed. Figure 6 a show the correct view of the study areawhile figure

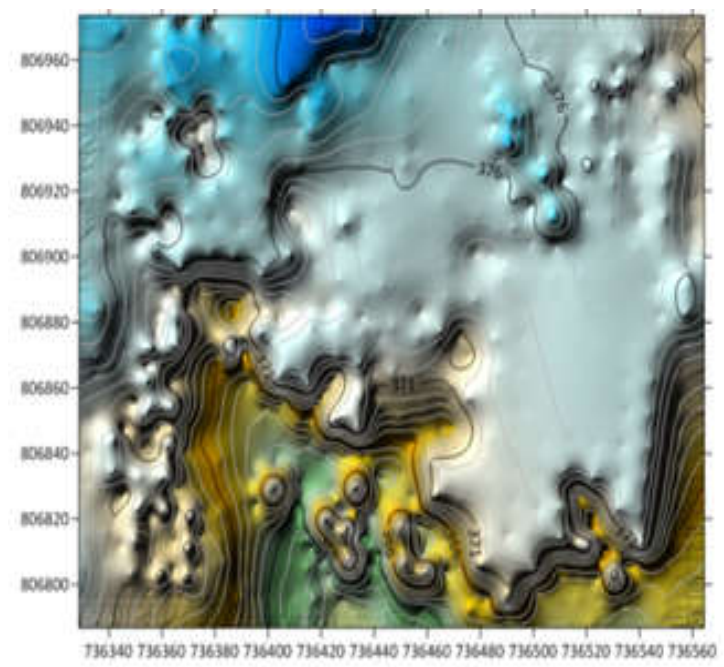

Fig6a:Contour overlaid on Shaded Relief (Conventional).

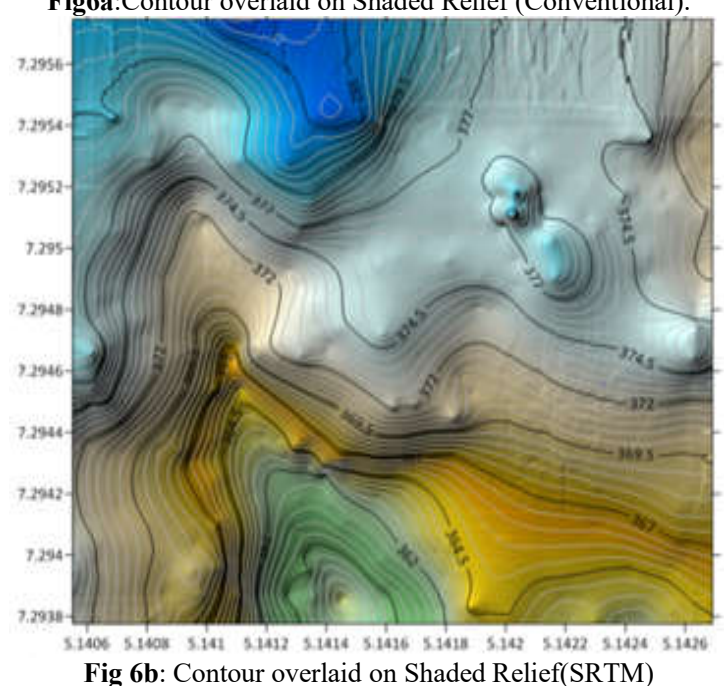

The Elevations $(\mathrm{Z})$ from conventional method and SRTM (Table 2) were analyzed to determine which method was most appropriate or if none transcend the other. Statistical analysis was carried out to examine whether two observed samples have the same means and variance.Significantly, the hypothesis tested in this research for both 'means and variances' was:
$\mathrm{H}_{0}: \mu_{1}=\mu_{2}$ : The population mean of conventional method heights is equal to the SRTM heights $\mathrm{H}_{1}: \mu_{1} \neq \mu_{2}$ The population mean of conventional method heights is NOT equal to the SRTMheights(Claim).

Table 2: Elevation of Conventional method versus SRTM

\begin{tabular}{lll}
\hline Identification & Z CONV MTD & Z SRTM \\
\hline PG/17/43 & 379.144 & 381.308 \\
PG/17/44 & 382.813 & 380.468 \\
PG/17/45 & 374.944 & 375.839 \\
PG/17/46 & 370.623 & 373.589 \\
PG/17/47 & 376.399 & 374.110 \\
PG/17/48 & 363.741 & 374.263 \\
PG/17/49 & 362.807 & 373.833 \\
PG/17/50 & 373.565 & 372.605 \\
MEAN & 373.005 & 375.752 \\
STD & 7.020089173 & 3.301414954 \\
VAR & 49.281652 & 10.8993407 \\
\hline
\end{tabular}

Further analysis was carried out on the result obtained by comparing the means and variances for a possible similarities or otherwise usinga two tail student t-test and F-test at $\alpha=0.05$ significant level. The result obtained from the student-t statistics showed that there was no significant difference between the mean of the $\mathrm{Z}$ (CONV. MTD) and Z (SRTM) because $\mathrm{T}_{\text {cal }}=$ $1.001689824>\mathrm{t}_{\mathrm{tab}}=-2.228$ therefore, there was enough evidence to accept the claim of null hypothesis and conclude that at least one mean is not significantly different from the other at $95 \%$ confidence level. Also, for the F-distribution statistics the result revealed that there was no significant difference between the variance of conventional method and SRTM because $\mathrm{F}_{\mathrm{cal}}=4.52<\mathrm{F}_{\mathrm{tab}},=4.99$ therefore, there was enough evidence to accept the claim of null hypothesis and conclude that at least one variance is not significantly different from the other at $95 \%$ confidence level.The statistical results obtained from Student-t and Fdistribution reveals that no method is better than the other. Although, the heights obtained from the SRTM seems to be grossly inadequate because the satellite measure the surface of the study area while direct and accurate measurements were made by the conventional method. However, the products (Contour map, 3-D Wireframe, 3-D Digital terrain model and overlaid of contour map on shaded relief) derived fromeither of the conventional method and SRTM can be used to represent the study area.

Conclusion: The comparison between the conventional method and SRTMrevealed that the conventional method represents the study areabetter than the SRTM. Also, the contour and the 3-D Digital terrain model of the conventional method show more steepness. Significantly too,the conventional method consumed more time and resources during data acquisition. This research recommends that the study 
area should be subjected to precise methods of data acquisition andcontinuous monitoringto determine the amount of runoff that occurswithin epochs.

Acknowledgement: I wish to acknowledge the effort of Mr. David Mark of Geomatics and Remote Sensing Research Groups, Department of Surveying and Geoinformatics Federal University of Technology, Akure Ondo State Nigeria for making the data and resources for this research available.

\section{REFERENCES}

ASPRS (1996). Digital Photogrammetry - An Addendum to the Manual of Photogrammetry (ed. C. Greve). Publication of the American Society for Photogrammetry and Remote Sensing, Maryland

Forkuor, G; Maathuis, BM (2012). Comparison of SRTM and ASTER derived digital elevation models over two regions in Ghana: Implications for hydrological and environmental modelling. In Piacentini, T., Miccadei, E. (Eds.). Stud. Environ. Appl.Geomorphic. ISBN 978-953-51-0361-5. Pp219-240

Gerald, F; Ben, M (2012). Comparison of SRTM and ASTER Derived Digital Elevation Models over Two Regions in Ghana - Implications for Hydrological and Environmental Modeling

Gorokhovich, Y;Voustianiouk, A (2006). Accuracy assessment of processed SRTM-based Elevation data by CGIAR using field data from USA and Thailand and its relation to the Terrain Characteristics. Remote Sensing of Environment 104 (4) 409-415

Hilton, RD; Featherstone, WE; Berry, PA; Johnston, CP; Kirby JF (2003). Comparison of digital elevation models over Australia and external validation using ERS-1 satellite radar altimetry, Australian Journal of Earth Sciences 50(2): 157-168.

Hirt, C; Filmer, MS; Featherstone, WE (2010). Comparison and Validation of the recent freely available ASTER-GDEM Ver1, SRTM Ver4.1 and GEODATA DEM-9S Ver3 Digital Elevation Models over Australia. Australia Journal of Earth Sciences, 57(3), .337-347
Isioye, OA; Obarafo, EO (2010). Shuttle Radar Topography Mission(SRTM) Elevation data. A contemporary Global Elevation Model for describing the topography of Zaria and its environs. Ife Research Publications in Geography (IRPG), 9(1) 221-245

Isioye, OA; Yang, IC (2013).Comparison and validation of ASTER-GDEM and SRTM elevation models over parts of Kaduna State, Nigeria. SASGI Proceedings 2013 - Stream 1

Kahmen, H; Faig, W (1988). Surveying. W. de Gruyter, Berlin, New York, 1988.

Lohr, U (1998). Digital Elevation Models by Laser Scanning. Photogrammetric Record 16(91), 105109, 1998.

Mukul, M; Srivastava, V; Mukul, M (2015). Analysis of the accuracy of Shuttle Radar Topography Mission (SRTM) height models using International Global Navigation Satellite System Service (IGS) Network in India. Journal of Earth System Science. 124 (6). 1343-1357

Nwilo, PC; Olayinka, DN; Okolie, CJ; Adzandeh, EA (2012). Transformation of shuttle Radar Topography Mission (SRTM) Digital Elevation Data to Nigerian Height System. FUTY Journal of the Environment. 7(1). 73-89.

Nwilo, PC; Ayodele, EG; Okolie CJ (2017). Determination of the Impacts of Landscape Offsets on the 30-metre SRTM DEM Through a Comparative Analysis with Bare-Earth Elevations. FIG Peer Review Journal, 21pps. ISSN No 2412-916X.

Ozah, AP; Kufoniyi, O (2008).Accuracy assessment of Contour Interpolation from 1:50,000 Topographical maps and SRTM data for 1:25,000 Topographical mapping. The International Archives of the Photogrammetry, Remote Sensing and Spatial Information Sciences (IAPRS), Vol. XXXVII Part B7. Beijing 2008. 